\title{
Machinist Dies After Being Struck by Rotating Steel Bar Stock in Lathe in Washington State
}

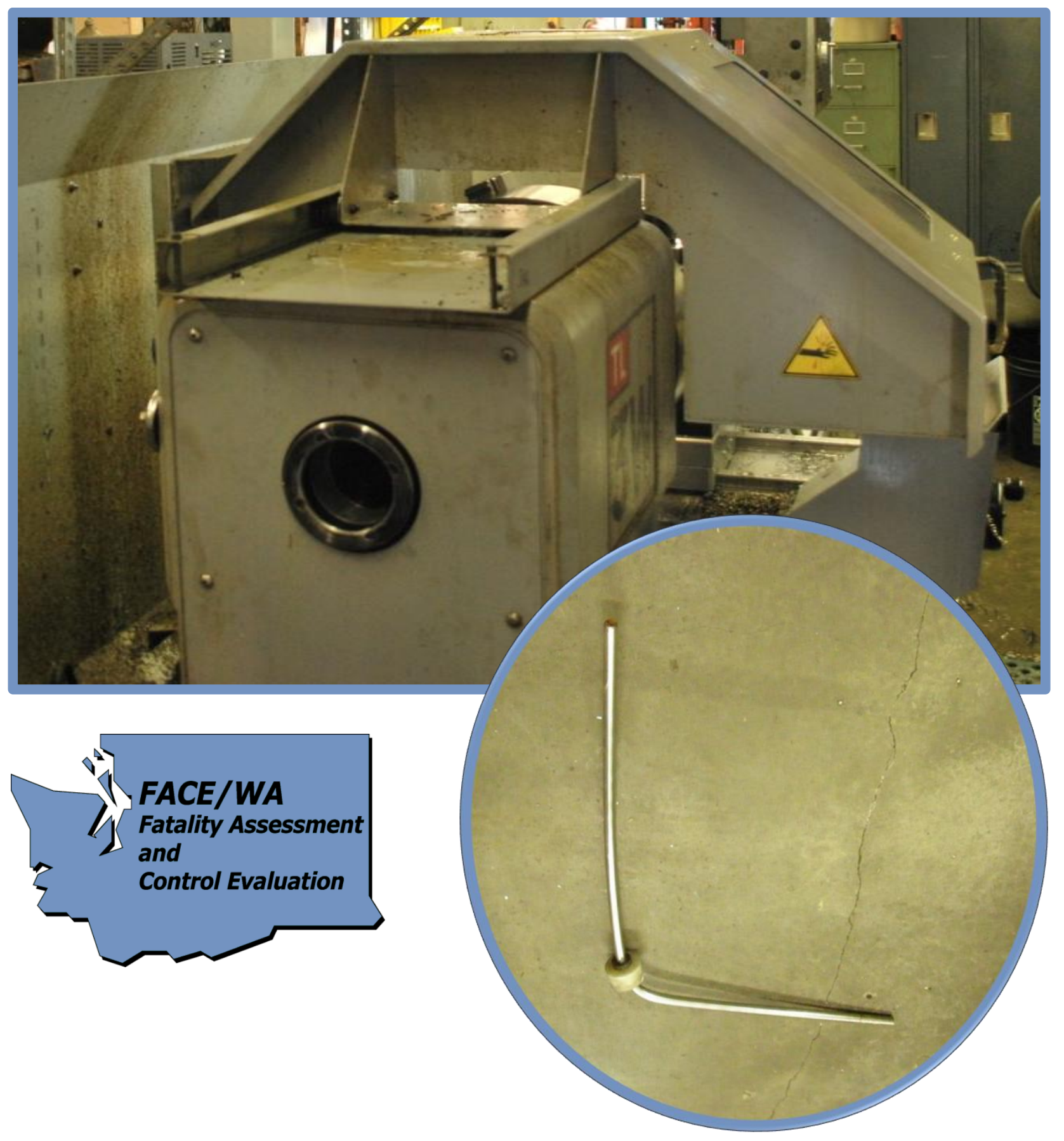

Investigation: \# 10WA01001

Release Date: July 15, 2012

SHARP Report: \# 52-25-2012 


\section{TABLE OF CONTENTS}

$\underline{\text { CONTENTS }}$

PAGE

DEFINITIONS

SUMMARY

RECOMMENDATIONS

4

INTRODUCTION

5

EMPLOYER

5

VICTIM

5

LATHE

6

LATHE TRAINING AND EXPERIENCE

6

CNC CUTTING PROGRAM

ROUND BAR STOCK

MATERIAL STOCK ROOM

INVESTIGATION

8

INCIDENT

POST INCIDENT REMEDIATION

CONTRIBUTING FACTORS

CAUSE OF DEATH

RECOMMENDATIONS AND DISCUSSION

ACKNOWLEGEMENTS

APPENDIX A. PHOTOS AND FIGURES

REFERENCES

INVESTIGATOR INFORMATION

FACE PRORGRAM INFORMATION 


\section{DEFINITIONS:}

ANSI

APP

CAD

CAM

CNC

$\mathrm{DOSH}$

FACE

$\mathrm{NIOSH}$

RPM

SHARP

WA
American National Standards Institute

Accident Prevention Program

Computer-aided Design

Computer-aided Manufacturing

Computer Numerical Control

Division of Occupational Safety and Health

Fatality Assessment and Control Evaluation

National Institute for Occupational Safety and Health

Revolutions per Minute

Safety and Health Assessment and Research for Prevention

Washington State 


\section{SUMMARY}

On January 29, 2010, a 27-year-old machinist was fatally injured when he was struck by a piece of round stainless steel bar stock that he was machining in a computer numerical control (CNC) lathe. According to the general manager, the victim was machining washers from the round bar stock for a gill net reel frame. He had placed a 6 foot piece of the bar stock into HAAS TL-3W model lathe. Approximately 3 feet of the steel bar stock extended past the spindle and out of the lathe and was unsupported. As the victim was machining the round bar stock, the 3 foot unsupported portion extending through the spindle bent to nearly an 80 degree angle.

The general manager speculates that the victim heard the noise generated by the rapidly rotating round bar stock and went to investigate the source. As the victim approached the source of the noise coming from the back of the machine, he was struck by the bent piece of round bar stock. The general manager and a contractor heard a crash sound in the vicinity of the lathe and upon responding, found the victim unconscious.

To prevent similar incidences the Washington State Fatality and Control Evaluation Team (FACE) recommends that:

- Employers should ensure that machinery hazards are abated with engineering controls.

- Employers should develop and enforce machine and hazard specific safety policies and procedures that address and abate hazards.

- Employers should develop a mandatory checklist for each set-up procedure to ensure that all steps are properly completed before machines are started.

Designers and manufacturers of CNC lathes should:

- Design CNC lathes with multiple safety systems including interlocks and fail safes. 


\section{INTRODUCTION}

On January 29, 2010, the Washington State Fatality Assessment and Control Evaluation (FACE) Program was notified by the Washington State Department of Occupational Safety and Health (DOSH) of the death of a 27-year-old machinist.

After reviewing the DOSH investigation report, WA FACE investigators interviewed the general manager and current machinist for the employer of the victim. During the interview, the general manager provided information regarding the history, organization, and health and safety programs of the company, as well as insight into the incident. The general manager and machinist also provided details and demonstrated the functionality of the HAAS TL-3W model lathe. During the course of the FACE investigation, documents reviewed included police report, coroner's report, and DOSH investigation documents and photographs.

\section{Employer}

The employer owns a small machine shop that has been in business for approximately 3 years. They employ 4 full time employees and 2 contractors. Three of the 4 full time employees were machinists. The shop makes small batch orders of specialty parts for marine industry hydraulic deck equipment, such as washers and bolts. Machinery and equipment used in the shop includes a Computer Numerical Control (CNC) lathe, a manually operated center lathe, a vertical mill, a band saw, a hydraulic press, welding equipment, a material hoist, and a forklift. At the time of the incident, the company did not have a written safety plan or a designated safety person, nor did they hold regular safety meetings with employees.

\section{Victim}

The victim was a full-time employee of the machine shop for 2 years and his tasks included setting up, programming, and running the CNC lathe and CNC mill. He was also responsible for setting up and running other non-CNC machines. His job title was machinist at the shop and he was a member of the local International Association of Machinist and Aerospace Workers.

Before starting his full-time employment with the machine shop, the victim took a 3-4 month long college level course on CNC machining at a local technical school. In this training class the victim worked with a HAAS TL-1 lathe, which is a smaller version of the TL-3W lathe involved in this incident. The victim received a certificate for successfully completing the machining course. The victim also attended a four hour 
training course given by the lathe manufacturer when it was installed. In addition, the victim had previous work experience and interest in computer programming.

\section{The Lathe}

The lathe involved in this incident is a HAAS model TL-3W Computer Numerical Control (CNC) lathe (photos $1 \& 2$ ). It was purchased new by the employer and installed by a representative for HAAS. A lathe uses either automatic or manual controls to produce a machined product by rotating the workpiece against a stationary tool. ${ }^{[1,2]}$ This type of CNC lathe is controlled electronically via a computer-aided design (CAD) or a computeraided manufacturing (CAM) program.

The employer referred to the lathe as a "toolroom model." A toolroom lathe is considered a top of the line center lathe and is most often used by general machinists who manufacture smaller batches of a product from metal or other man made materials. The TL-3W lathe is 132 inches long and 116 inches high. The lathe operates at 360-480 volts, 20 amps, and has a maximum cut diameter of 30 inches and a maximum cut length of 60 inches.

The maximum rotational speed of the lathe is 1,800 revolutions per minute (RPM). ${ }^{[3]}$ However, the employer limited the speed to 1,000 RPM. The employer manufactured a sleeve bearing system to help support materials that extended into or through the spindle (photo 3). According to a HAAS representative, sleeve bearings like this are commonly used and recommended by the manufacturer to support material in the spindle but should not be used as the only support system for material extending past the spindle.

\section{Lathe Training and Experience}

The victim first gained lathe operating experience in the 3-4 month college level course on $\mathrm{CNC}$ machining that he took before beginning his employment. Prior to working for the employer the victim also had experience working in computer programming. According to the general manager, the victim used the CNC TL-3W lathe on a daily basis.

When the lathe was purchased, the HAAS representative provided a 4-hour operation and safety training class. The training class included instructions on how to safely program the machine, make adjustments, change out cutting tools, and how to use safety features to minimize hazards. 
During the 4-hour training by the HAAS representative, the victim and coworkers were informed that it was not safe to operate the lathe with a piece of unsupported bar stock extending out past the spindle. Despite the hazard-specific training, the victim was previously observed setting up the HAAS TL-3W lathe with unsupported bar stock extending out past the spindle. Shop employees reported that they stopped the victim and reminded him that this was not an approved or safe practice.

The employer had both the HAAS Safety Manual and the HAAS Toolroom Lathe Operator's Addendum at the shop. The safety manual for the TL-3W lathe stated that "unsupported bar stock must not extend past draw tube end". However, this particular machine did not have a draw tube. The operator's addendum directed operators to "use additional support if turning long parts" and contained a warning for operating the lathe with bar stock extended beyond spindle (figure 1). ${ }^{[4]}$ Yellow labels located on the lathe near the spindle also warned operators and bystanders of struck by and pinch point hazards.

\section{Round Bar Stock}

The round bar stock was a 1 inch diameter 303 stainless steel rod measuring approximately 6 feet in length. The 303 stainless steel, also referred to as chromiumnickel alloy steel, round bar stock is commonly used in free machining. The victim was attempting to cut approximately 1.7 inches of the stainless steel round bar stock to make the washers (Photo 7).

\section{CNC Cutting Program}

The victim was using a G96 code CNC Cutting Program to make the stainless steel washers. This program maintained a constant surface speed while the cutting tip made a right angle cut to the axis of the rotating work piece, called facing (figure 2) ${ }^{[5]} \mathrm{A}$ constant surface speed program increases the round bar stock rotating speed as the cutting tool approaches the center of the workpiece. This means that the round bar stock was constantly accelerating as it was being cut.

\section{Material Stock Room}

The material stock room and the shop's workroom where the HAAS TL-3W lathe was located were separated by a wall and a sliding door. Through the sliding door were material racks that held the longer and shorter pieces of stock. The short stock rack was approximately 15-20 feet away from the door (photo 4). The material stock room also 
had a band saw that could have been used to cut longer pieces of stock into shorter lengths (photo 5).

\section{INVESTIGATION}

On January 29, 2010, the victim arrived at work around 7:00 am. He began his day by completing a frame for a gill net reel that had been started the previous day. The victim used the band saw to cut out the sides for the gill net reel and prepped them for welding. Later in the morning, the general manger asked the victim to help him make some handles that required threads on a 5 foot long $1 / 2$ inch piece of round bar. The general manager asked the victim to help with this project because, according to the general manager, he was skilled at cutting threads on the CNC lathe.

After helping the general manager cut the threads, the victim took his lunch at approximately 11:00 am. After his lunch, at approximately $12: 10 \mathrm{pm}$, the victim obtained a 6 foot piece of 1 inch diameter 303 stainless steel round bar stock from the material rack to make the washers. He used the shop's manual lathe, a Nardini model SZ25120T, to punch a whole into the 303 round stainless steel bar stock. This stock would then be cut on the HAAS CNC lathe to make the washers for the gill net reel.

The victim proceeded to the HAAS CNC to make the washers. He positioned the 6 foot bar stock with approximately 3 feet of excess stock extending out through the spindle hole of the lathe. A sleeve bearing was used to stabilize the bar stock as it was machined. The sleeve bearing fit securely into the spindle opening and had a hole in the center intended to stabilize the bar stock as it turned. He initiated the CNC program to cut the stock at a maximum speed of 1,000 RPM.

At approximately 12:33 pm, when the victim started up the lathe, the general manager was completing paperwork in the office and the contractor was working on a recently purchased drill press with his back turned to the victim. The general manager and the contractor did not see the victim set up the lathe with the three feet of unsupported bar stock extending through the spindle or observe the incident.

\section{Incident}

Soon after the victim started the lathe, the bar stock extending out the spindle bent to about an 80 degree angle (photo 3). The location of the bend in the stock was close to the center of the bar and adjacent to the sleeve bearing used to stabilize the spinning piece of stock. The bend caused approximately 3 feet of the bar stock to rotate outward 
from the lathe and perpendicular to the section of stock being machined, similar to a propeller.

According to the general manager, the victim likely heard the noise from the back of the lathe made by the bent stock rotating at 1000 RPM and stepped towards the back without hitting the stop button on the lathe. When the victim stepped towards the back of the lathe to investigate the source of the sound, he was struck by the bent bar stock.

Both the general manager and contractor heard a noise and a crash. The contractor turned and saw the victim lying on the ground. The general manager came out of the office to see what happened and the contractor yelled for him to call 911 . The general manager called 911 and emergency personal arrived on scene in less than 10 minutes. The victim was pronounced dead on scene.

\section{Post-Incident Remediation}

Following the incident, the employer fabricated a system to support bar stock extending from the spindle while it is machined (photos $7 \& 8$ ). The system can be anchored to the lathe to enhance stability to help prevent similar future incidents. The employer also developed a written accident prevention program (APP) and now holds monthly safety meetings with employees. The general manager has been designated as the shop safety coordinator.

Following the incident, the general manager and employees reviewed all current shop procedures to identify and determine how to avoid the associated hazards. Prior to new jobs being performed, employees and the safety coordinator analyze the job tasks to identify hazards and how best to control them.

\section{CONTRIBUTING FACTORS}

- Three feet of unsupported bar stock extending out of the lathe's spindle.

- No system for supporting bar stock extending out of the spindle.

- No written accident prevention program that addresses lathe-specific hazards and safe operation.

\section{CAUSE OF DEATH}

The medical examiner listed the cause of death as blunt force injury of the head, torso, and extremities. 


\section{RECOMMENDATIONS AND DISCUSSION \\ Recommendation 1: Employers should ensure that machinery hazards are abated with engineering controls.}

\section{Discussion:}

To control hazard associated with a CNC lathe or for other machines, employers should follow the engineering hierarchy of controls. ${ }^{[1]}$ These controls, starting with the most effective, are:

- Eliminate or control hazard(s) by design.

- Control exposure to hazards by use of guards or safeguarding devices.

- Provide other safeguarding (e.g. awareness barrier).

- Implement administrative controls or other protective measures.

Following the incident, the employer manufactured a system that supports bar stock that extends past the spindle. If this support system had been in place, the incident may have been prevented. Employers who manufacture their own support system should work with engineers or companies who specialize in creating these support systems to ensure that the system is feasible and safe. Other methods to help abate this hazard include:

- Barriers to prevent workers from entering the path of a potential hazard.

- Ordering shorter pieces of stock material.

- Cutting stock material after delivery so it does not extend past the spindle.

Another option, provided by the general manager, is to cover the spindle opening with a locking device. When an operator has a job that requires material to extend past the spindle, he must get authorization from the safety manager-similar to a lockout/tagout procedure. In order to get authorization and have the lock removed, the operator would need to demonstrate that:

- It was necessary to have material extend past the spindle.

- The material would be properly and safely supported.

Manufactured support systems for extended bar stock (photos 9 \& 10) are available from companies such as J.F. Berns (ifberns. supports.com). These support systems can be manufactured with variable options and prices. Available options include top loading, retractability, and the ability to hold larger diameter bar stock. 


\section{Recommendation 2: Employers should develop and enforce machine and hazard- specific safety policies and procedures that address and abate hazards.}

\section{Discussion:}

The employer was aware of the hazards associated with having unsupported bar stock extended past the spindle but had no written safety policies or procedures ${ }^{*}$ to address or control the hazard until after the incident. The employer also reported that the victim was verbally corrected at least two times for setting up the HAAS TL-3W lathe with bar stock extended past the spindle.

Safety policies and procedures are the basis of a safe workplace and should be created and documented before starting work on a new or existing job/task. The employer should perform or have a designated safety person perform a hazard analysis on all machine and task combinations. The hazard analysis should be used to identify and characterize the hazards as well as develop and document methods to control the hazards.

Safety plans should include enforcement policies and be updated before a new job or machine becomes part of the company's work practices. Employers should also periodically review their safety plans to ensure that they effective in controlling hazards.

This employer's safety plan would include policies regarding:

- The process for authorization to operate the lathe with bar stock extending past the spindle.

- What jobs are allowed to operate the lathe with bar stock extend past the spindle.

- How an operator must support and control bar stock extended past the spindle.

- How to respond to an unexpected or hazardous condition.

- The consequences for violating these policies.

\footnotetext{
*All Washington State employers are required to have a comprehensive Accident Prevention Programs (APP) that is enforced and effective in practice www.Ini.wa.gov.corerules.

For sample APPs, go to the Washington State Department of Labor and Industries website www.Ini.wa.gov.accidentprograms.
} 
Recommendation 3: Employers should develop a mandatory checklist for each set-up procedure to ensure that all steps are properly completed before machines are started.

\section{Discussion:}

Each product or production run set-up procedure should have a mandatory checklist that must be completed by the operator before a machine is started. A mandatory operator checklist would help ensure that all system parameters, machine settings, and safety precautions are checked. The completion of a checklist that included proper support for and length of material being machined may have influenced the victim to support the extended bar stock, use a shorter length of stock, or cut a longer piece of bar stock down to an appropriate length, thus preventing this fatality.

Additionally WA FACE recommends that manufacturers of CNC lathes should:

\section{Recommendation 4: Design and manufacture CNC lathes with multiple safety systems including interlocks and fail safes.}

\section{Discussion:}

In this situation the HAAS CNC TL-3W lathe did not have a safety system to prevent the lathe from being operated with unsupported bar stock extended past the spindle. Interlocks ensure that machines cannot be operated until all safety devices are in place. Manufacturing this type of lathe with interlocks would have prohibited the operation of the lathe with unsupported bar stock extending past the spindle and prevented this incident.

A fail safe device is intended to shutdown a machine if a hazardous condition occurs while in operation. Lathes should be designed and manufactured with fail safes that will shutdown the machine if any material extending past the spindle becomes potentially unsafe. The ability to detect a hazardous condition like material bending or becoming unstable and to shut down may have prevented this incident from happening. 


\section{ACKNOWLEDGEMENTS:}

This report has been reviewed and edited by health and safety professionals, subject matter experts, and stakeholders from labor and business communities. Though we are unable to acknowledge specific individuals for their contributions to this report, we would like to recognize the following for their help and support of the FACE mission and objectives:

- The Employer and their representatives.

- Washington State Division of Occupation Safety and Health (DOSH).

- National Institute for Occupational Safety and Health (NIOSH) FACE Program.

- Safety \& Health Assessment \& Research for Prevention (SHARP).

- Washington State Attorney General's Office. 


\section{APPENDIX A}

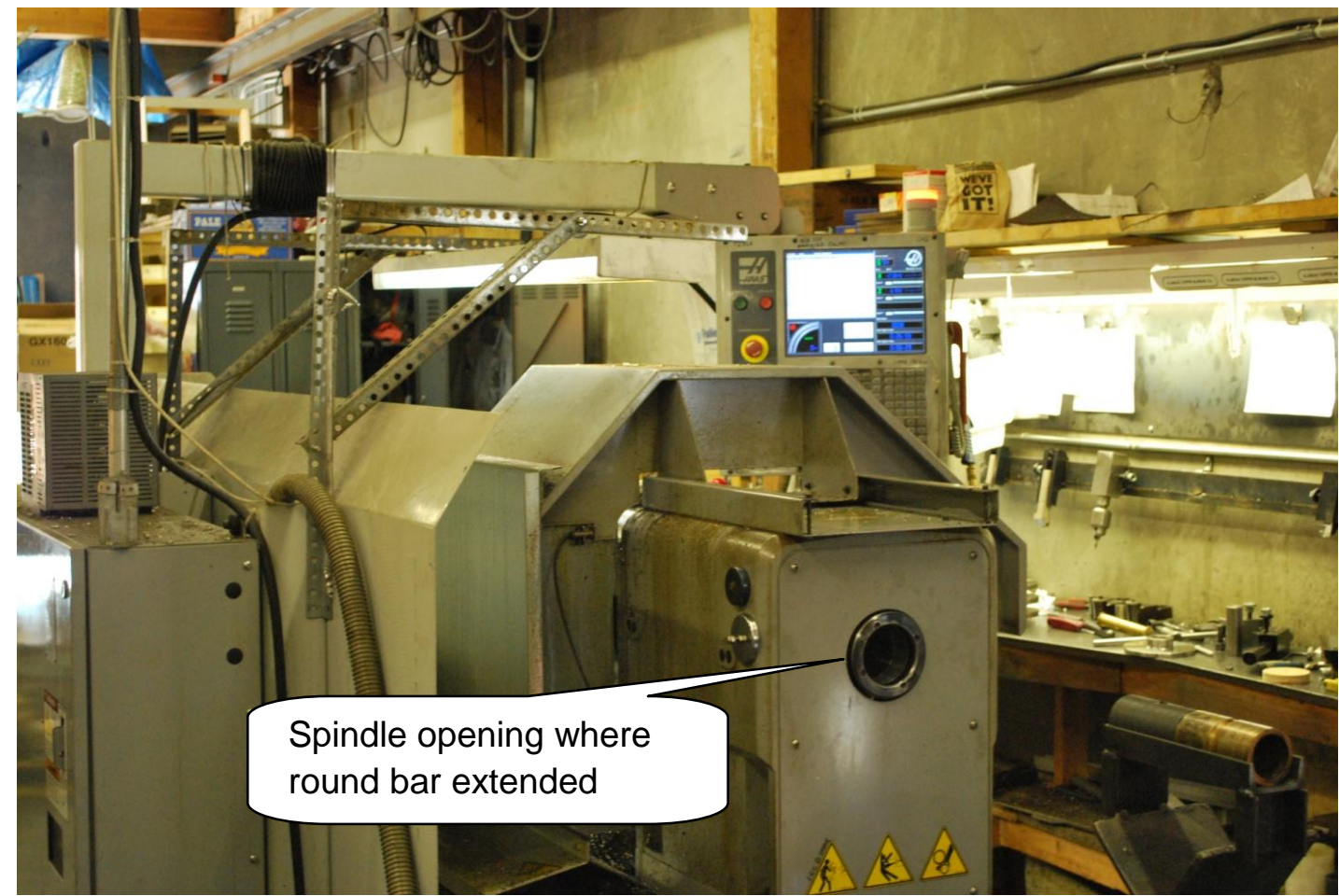

Photo 1. HAAS Model TL-3 lathe viewed from rear showing spindle opening

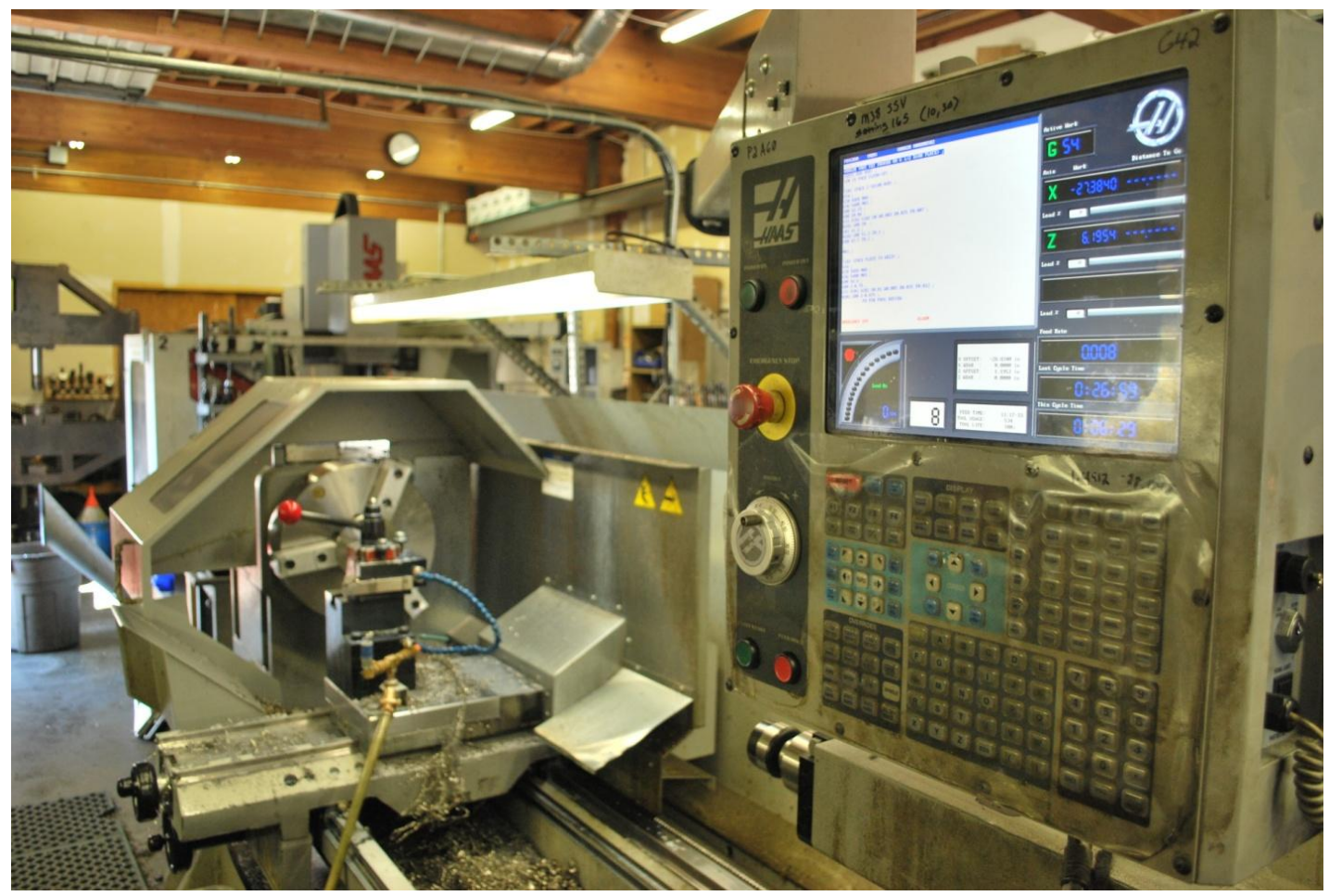

Photo 2. HAAS TL-3W lathe bed, control panel, cutting head, and chuck 


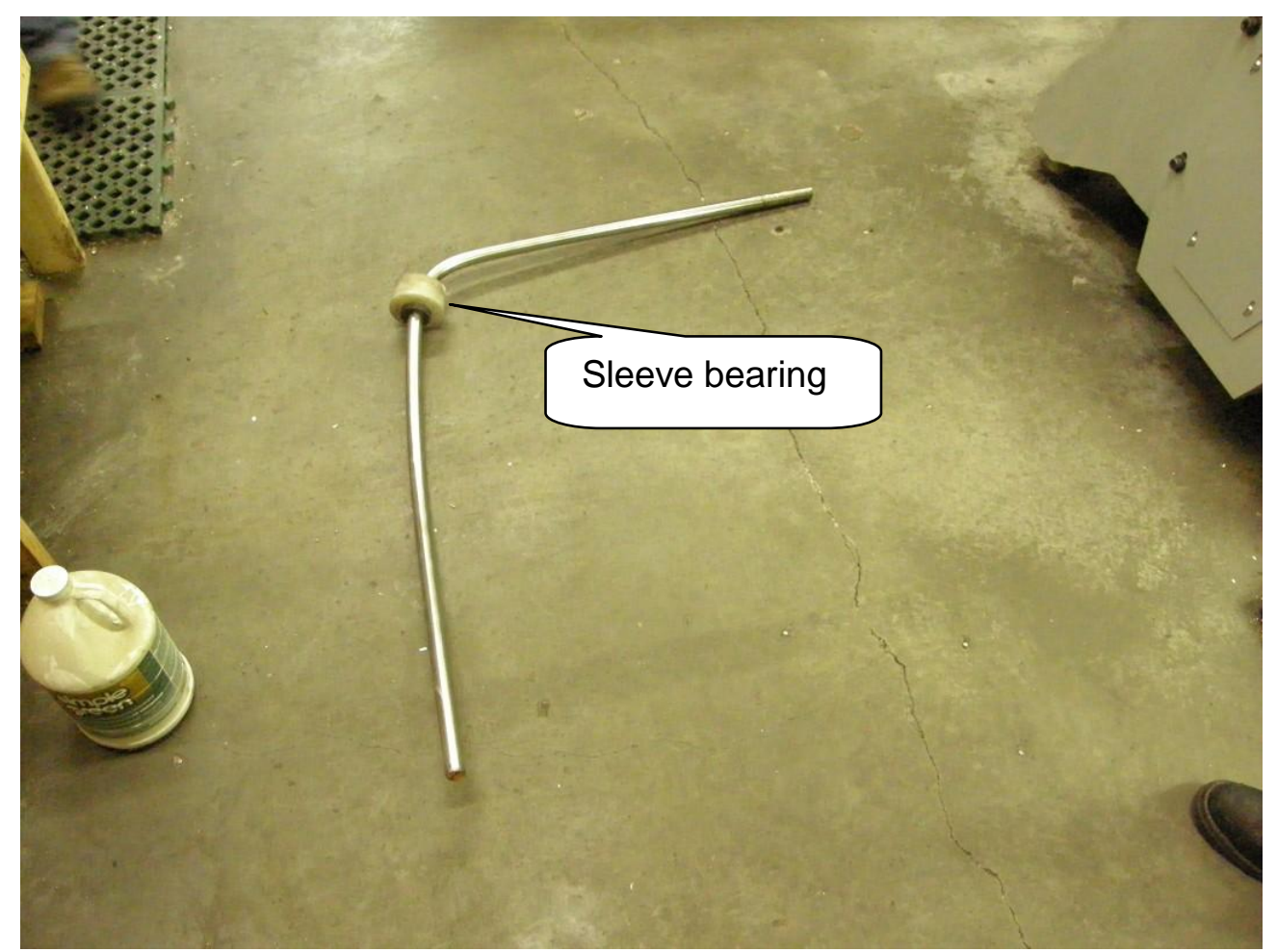

Photo 3. Bent bar stock with shop-designed plastic sleeve bearing

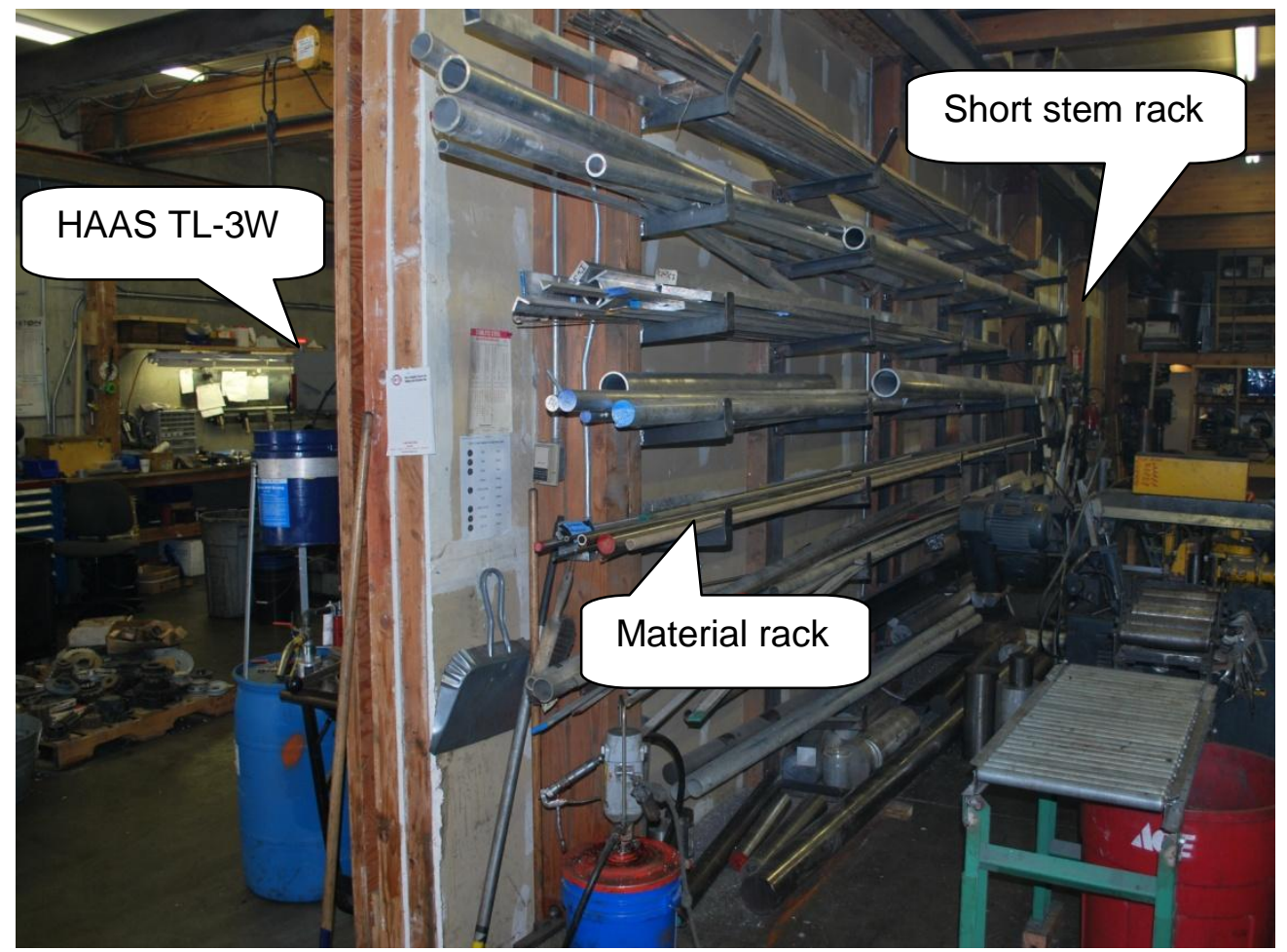

Photo 4. Shop layout showing material stock room relative to lathe 


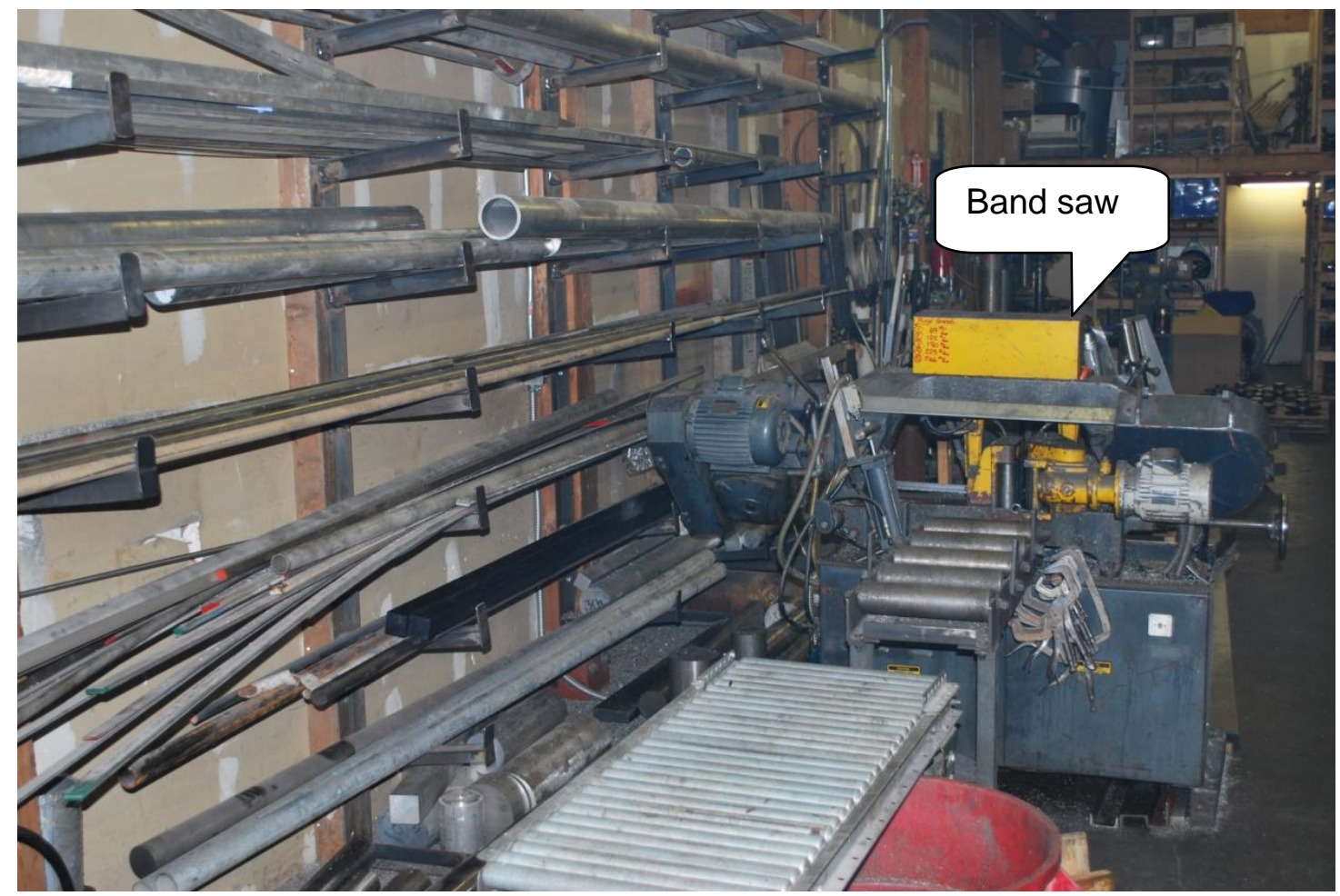

Photo 5. Material stock room and band saw for cutting stock

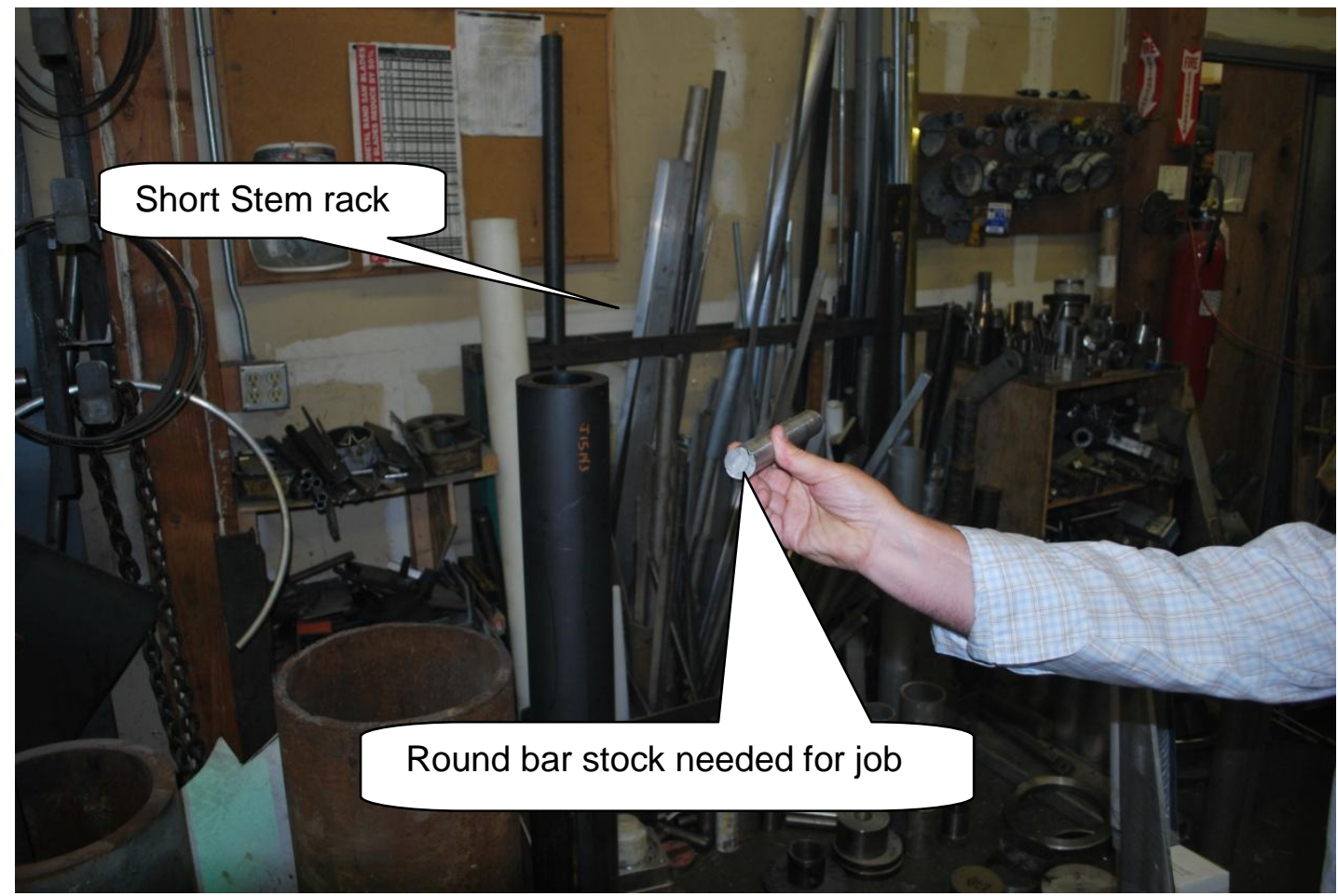

Photo 6. Short stem rack and length of 303 round bar stock needed for job 


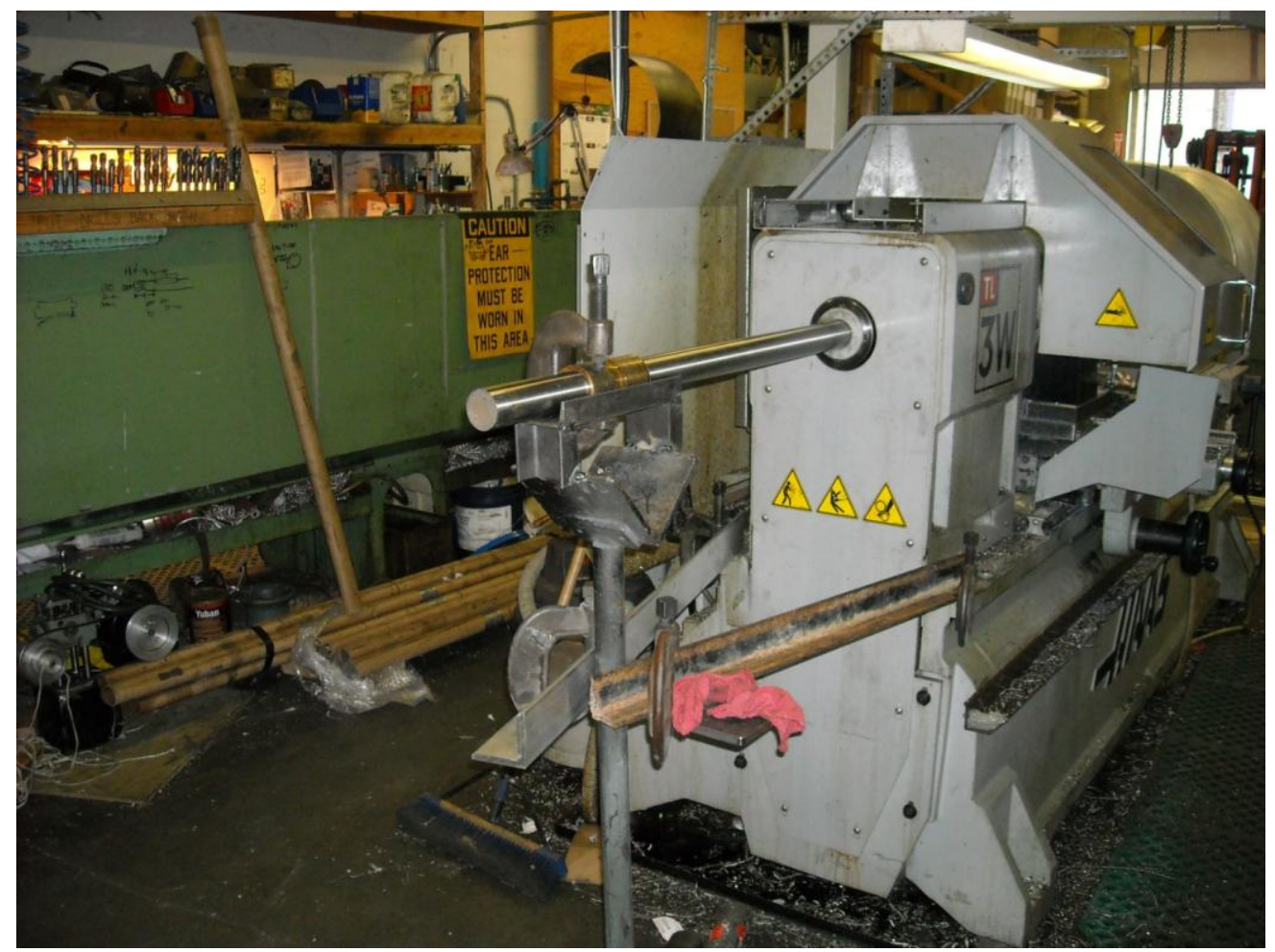

Photo 7. Shop-built support system for supporting extended bar stock

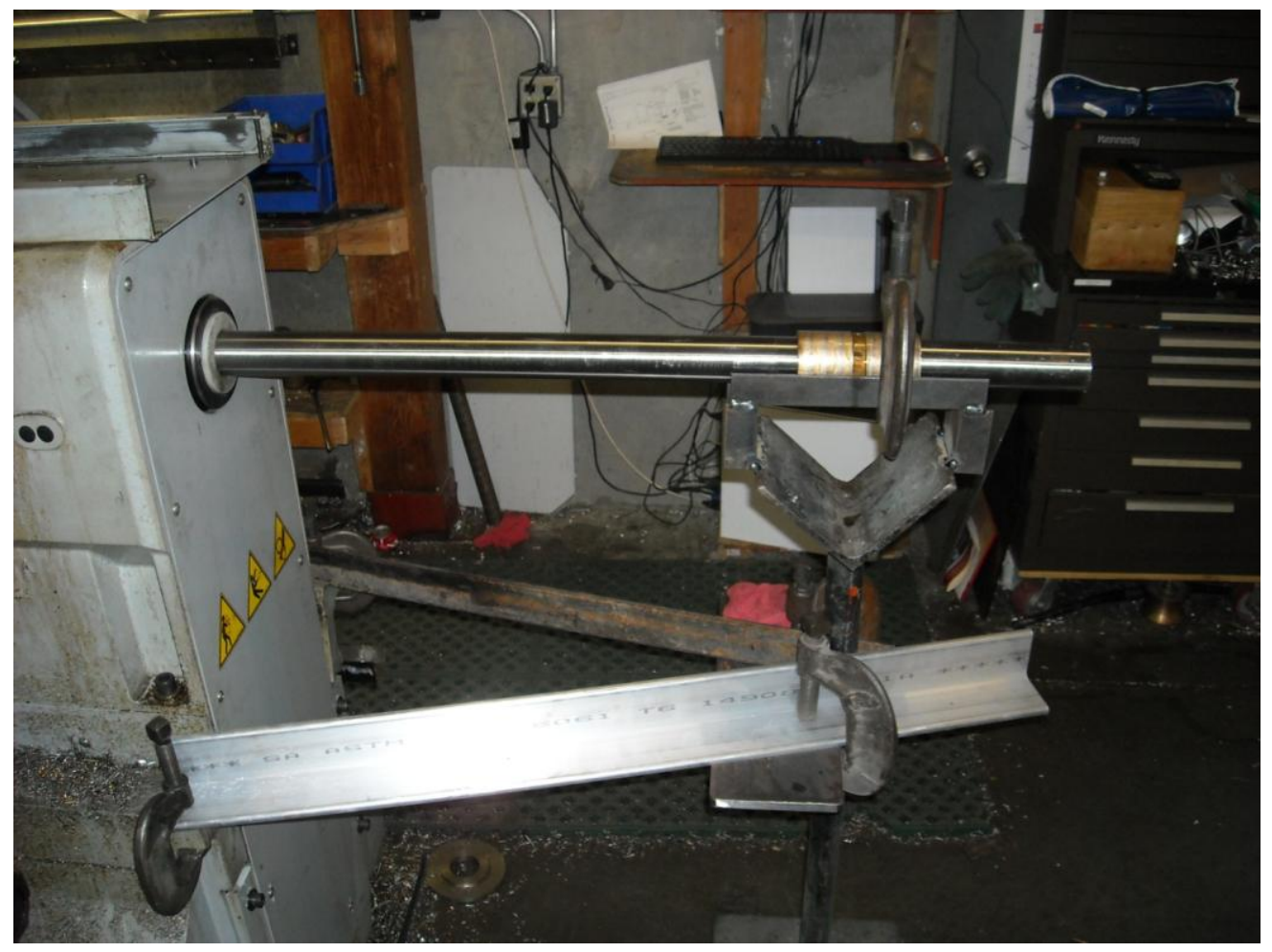

Photo 8. Shop-built support system for supporting extended bar stock 


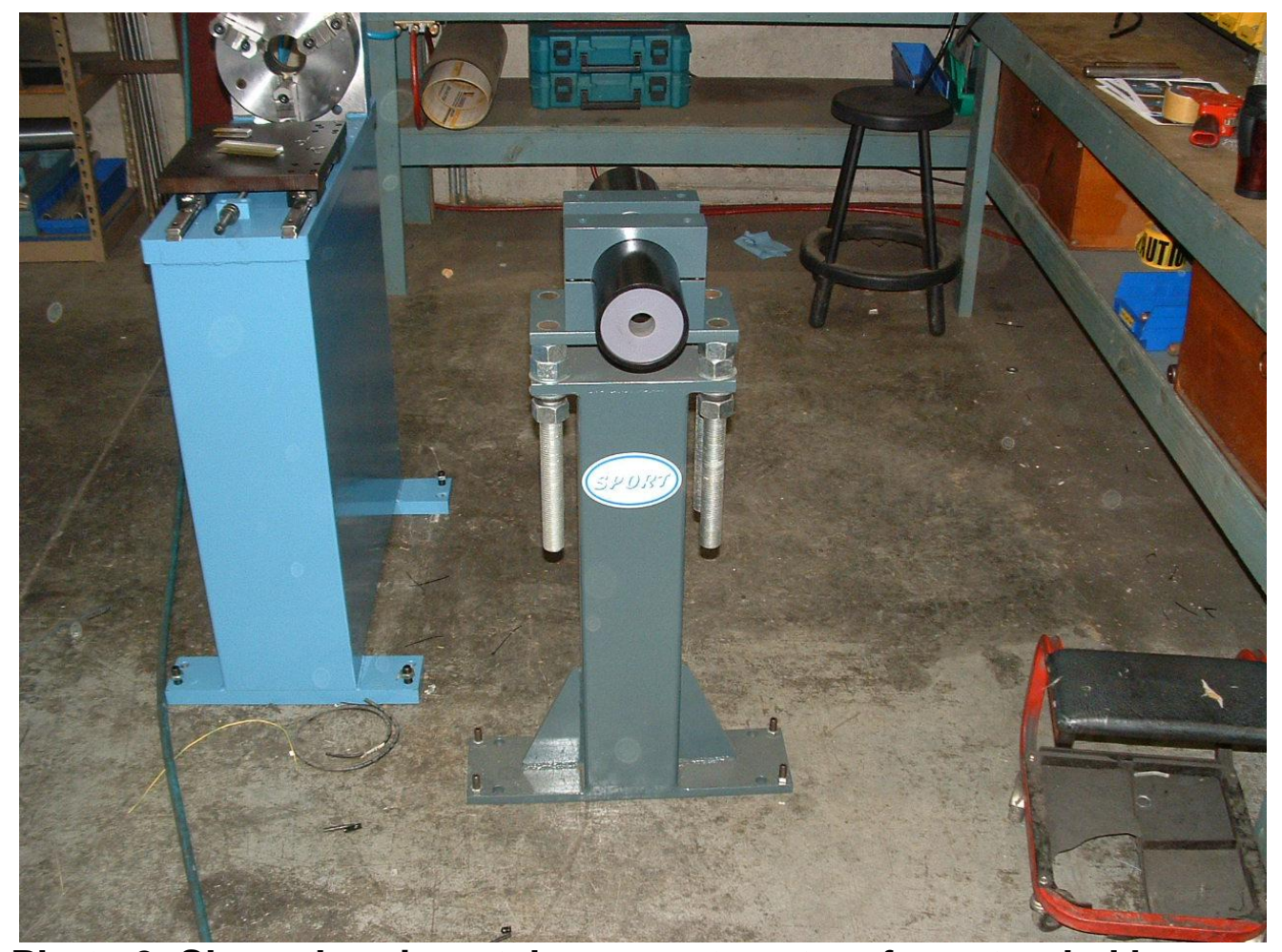

Photo 9. Sleeve bearing-style support system for extended bar stock engineered by J.F. Berns

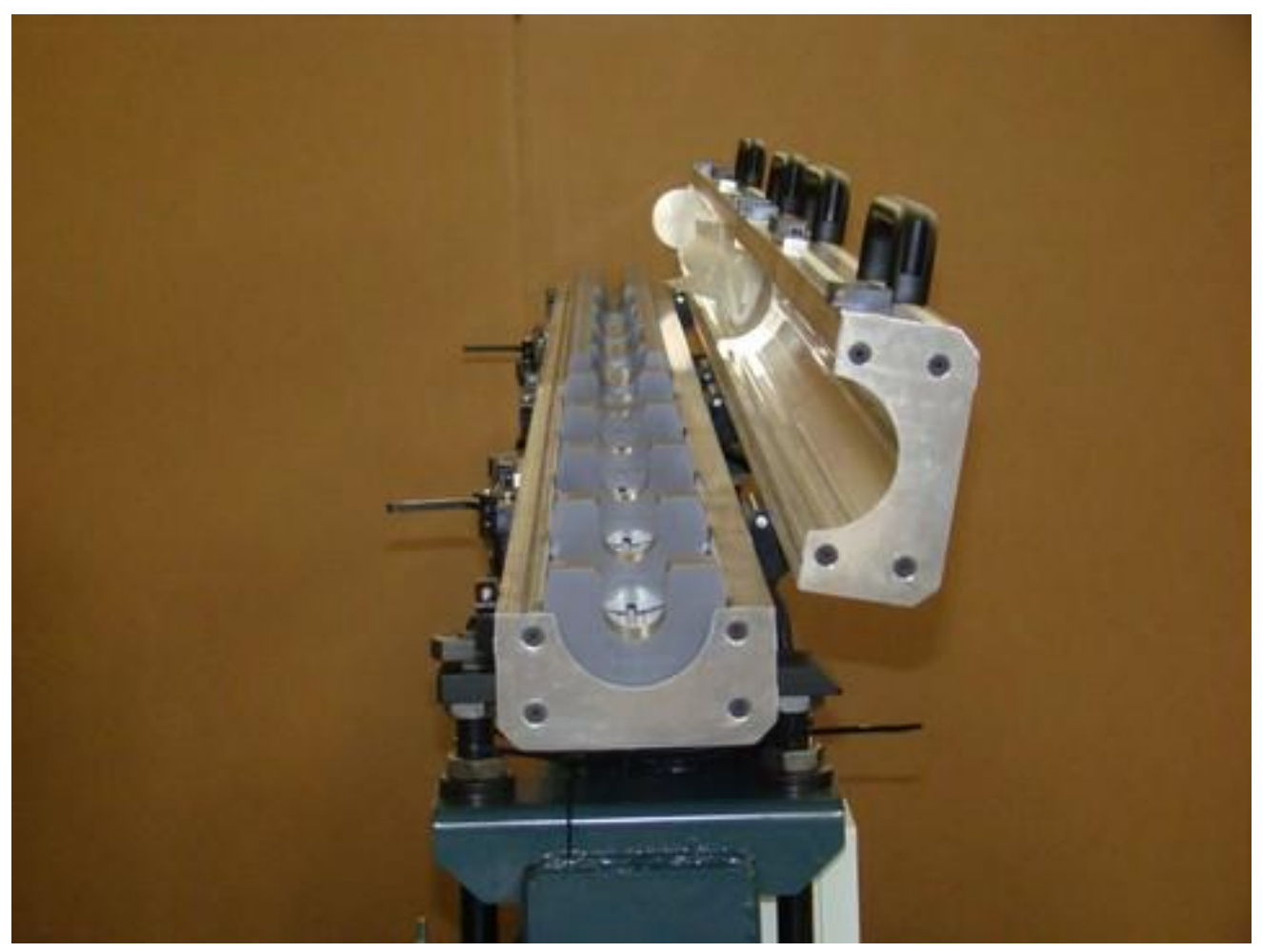

Photo 10. Cradle-style support system for extended bar stock engineered by J.F. Berns 


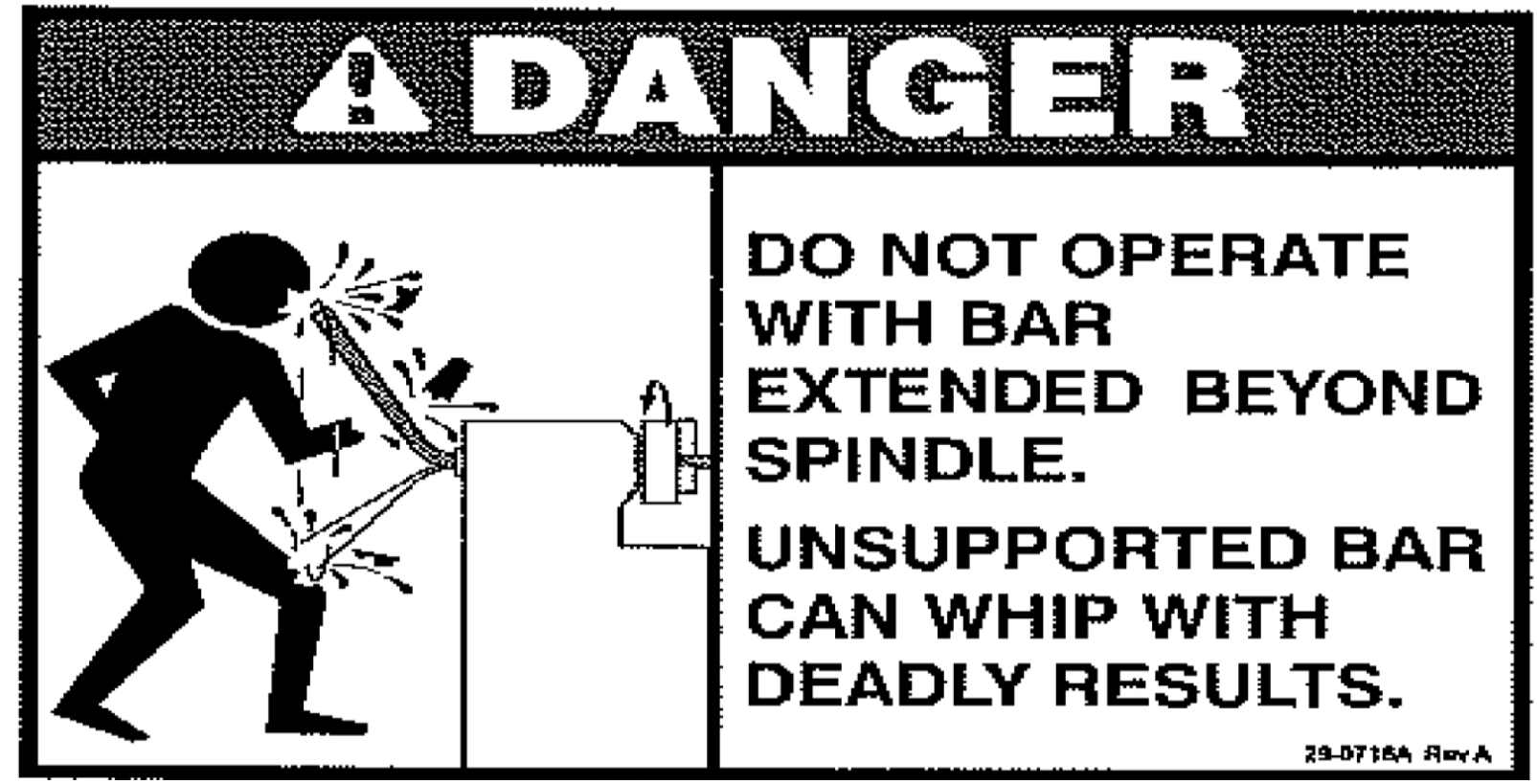

Figure 1. Danger warning from toolroom lathe operator's addendum

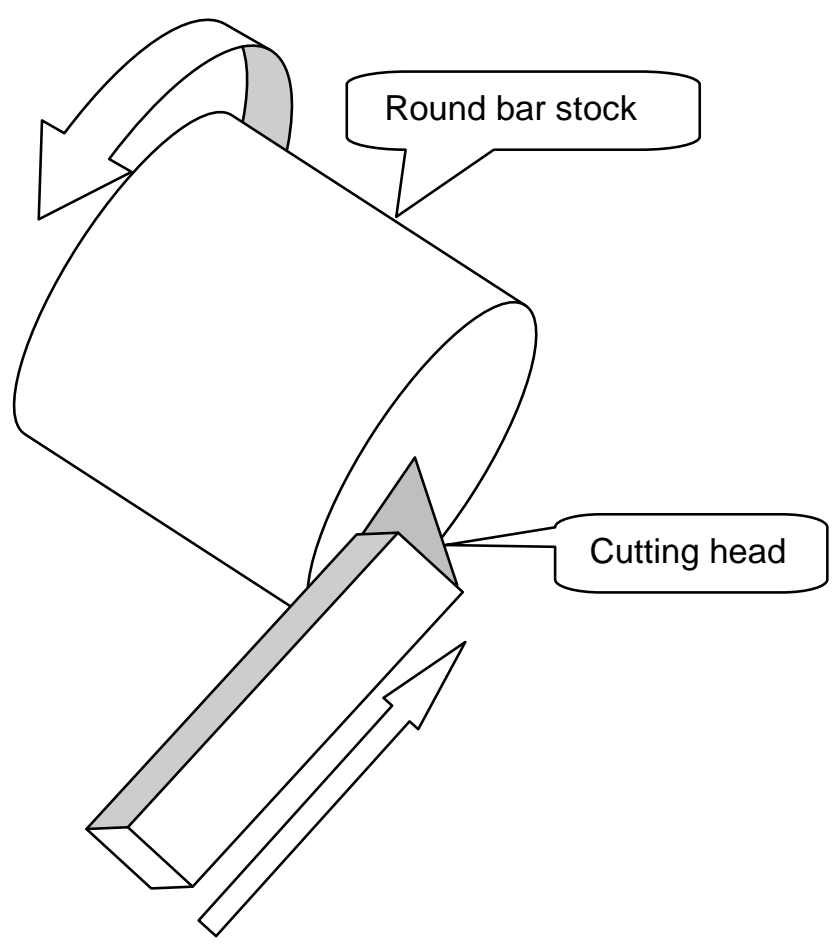

Figure 2. Diagram of facing process of round bar stock in lathe 


\section{REFERENCES}

1. American National Standards Institute, Safety Requirements for Turning Centers and Automatic, Numerically Controlled Turning Machines, in American National Standard For Machine Tools. 2002, The Association For Manufacturing Technology: McLean, VA. p. 59.

2. American National Standards Institute, Safety Requirements for Manual Turning Machines with or without Automatic Controls, in American National Standard for Machine Tools. 2001, The Association for Manufacturing Technology: McLean, VA. p. 45.

3. HAAS Inc, HAAS Safety Procedures. 2008. p. 1.

4. HAAS Inc, Toolroom Lathe/HPCL Operator's Addendum. 2007, HAAS Automation Inc. p. 1.

5. Robert H. Todd, D.K.A., Leo Alting, Manufacturing Processes Reference Guide. 1994, New York: Industrial Press. 


\section{INVESTIGATOR INFORMATION}

Todd Schoonover has a PhD in Industrial Hygiene from the University of Illinois at Chicago. He is a Certified Industrial Hygienist $(\mathrm{ClH})$ and Certified Safety Professional (CSP). Todd is currently the Principal Investigator for the WA FACE program.

Eric Jalonen has a Master's in Public Health from East Carolina University. He is a Research Investigator with the WA FACE program.

Randy Clark has a BA from The Evergreen State College. He is a Research Analyst with the WA FACE program.

\section{Washington State FACE Program Information}

The Washington State Fatality Assessment and Control (WA FACE) program is one of many workplace health and safety programs administered by the Washington State Department of Labor \& Industries' Safety \& Health \& Research for Prevention (SHARP) program. It is a research program designed to identify and study fatal occupational injuries. Under a cooperative agreement with the National Institute for Occupational Safety and Health (NIOSH), WA FACE collects information on occupational fatalities in WA State and targets specific types of fatalities for evaluation. WA FACE investigators evaluate information from multiple sources. Findings are summarized in narrative reports that include recommendations for preventing similar events in the future. These recommendations are distributed to employers, workers, and other organizations interested in promoting workplace safety. NIOSH-funded, state-based FACE programs include: California, lowa, Kentucky, Massachusetts, Michigan, New Jersey, New York, Oregon, and Washington. WA FACE does not determine fault or legal liability associated with a fatal incident. Names of employers, victims and/or witnesses are not included in written investigative reports or other databases to protect the confidentiality of those who voluntarily participate in the program.

Additional information regarding the WA FACE program can be obtained from:

Washington State FACE Program

www.Ini.wa.gov.FACE

PO Box 44330

Olympia, WA 98504-4330

1-888-667-4277 